\title{
Placental Growth Factor in Bladder Cancer Compared to the Diagnostic Accuracy and Prognostic Performance of Vascular Endothelial Growth Factor A
}

\author{
VIKTOR SOUKUP ${ }^{1}$, OTAKAR ČAPOUN ${ }^{1}$, MICHAEL PEŠL $^{1}$, ROMAN SOBOTKA ${ }^{1}$, \\ LUCIE VÁVŘOVÁ ${ }^{1}$, TOMÁŠ HANUŠ ${ }^{1}$, TOMÁŠ ZIMA ${ }^{2}$ and MARTA KALOUSOVÁ ${ }^{2}$ \\ ${ }^{I}$ Department of Urology, the First Faculty of Medicine, \\ Charles University and General University Hospital, Prague, Czech Republic; \\ ${ }^{2}$ Institute of Medical Biochemistry and Laboratory Diagnostics, the First Faculty of Medicine, \\ Charles University and General University Hospital, Prague, Czech Republic
}

\begin{abstract}
Background/Aim: To evaluate the diagnostic accuracy and prognostic performance of urinary and plasma levels of placental growth factor (PLGF) and provide their comparison with the results of vascular endothelial growth factor A (VEGF-A) in patients with primary and recurrent urinary bladder cancer. Materials and Methods: The enzymelinked immunosorbent assay (ELISA) was used to assess urinary and plasma concentrations of PLGF and VEGF-A in 240 individuals. Results: PLGF levels in urine and plasma were significantly higher in patients with primary bladder cancer than in healthy individuals $(p=0.003, p=0.005$, respectively). Area under the curve (AUC) of urinary PLGF was 0.68; AUC of plasma PLGF levels was 0.65. Patients with the urine levels of PLGF higher than $82.33 \mathrm{pg} / \mathrm{ml}$ had three times higher risk of recurrence. In patients with recurrent bladder cancer, the urinary concentrations of PLGF did not significantly differ from the concentrations in patients without current disease $(p=0.61)$. However, plasma PLGF levels were significantly higher in patients diagnosed with tumor recurrence ( $p=0.001)$; AUC of plasma PLGF levels was 0.69. Moreover, patients with plasma levels higher than $10.09 \mathrm{pg} / \mathrm{ml}$ had a five-times higher risk of future tumor recurrence. The diagnostic accuracy of PLGF was comparable with VEGF-A. Conclusion: From a clinical point
\end{abstract}

Correspondence to: Viktor Soukup, Department of Urology, the First Faculty of Medicine, Charles University and General University Hospital, Ke Karlovu 6, 12808 Prague 2, Czech Republic. Tel: +420 224967847, Fax: +420 224967102, e-mail: viktor.soukup@seznam.cz

Key Words: Bladder cancer, non-invasive detection, prognosis, biomarker, ELISA, placental growth factor, vascular endothelial growth factor A, PLGF, VEGF-A. of view, PLGF could be considered a valid diagnostic test for the detection of primary and recurrent bladder cancer. In patients with recurrent bladder cancer, plasma PLGF levels can differentiate individuals at risk of tumor recurrence.

Non-muscle invasive bladder cancer (NMIBC) has two important characteristics that substantially affect the treatment of disease. The first one is a high recurrence rate and the second one is a certain unpredictability of the disease course at the time of diagnosis (1). A significant proportion of patients has to be re-operated, some patients must undergo intravesical therapy and there is the need for a long-term cytoscopy-based follow-up (2). However, cystoscopy is an invasive, time-consuming and costly method, thus much effort is being made to replace it with a reliable marker. Despite the risk stratification based on clinical prognostic factors, individual course of the disease remains difficult to predict. An accurate estimation of recurrence and progression would enable treatment individualization and improvement of prognosis and quality of life. The lack of reliable prognostic factors is also important in patients with muscleinvasive bladder cancer (MIBC). Early diagnosis and timely radical treatment may improve survival of MIBC patients (3). Biomarkers are supposed to become the most beneficial tool in non-invasive detection and prognosis estimation of bladder cancer

Angiogenesis is essential for the growth of solid tumors and is assumed to play an important role in the progression, development of metastases and survival (4). Placental growth factor (PLGF) and vascular endothelial growth factor $\mathrm{A}$ (VEGF-A) are angiogenic growth factors interacting competitively with the same receptor; VEGF-A is essential in both normal and pathological conditions, but the functions of PLGF seem to be restricted to pathological conditions such as ischemic heart disease, arthritis and tumor growth 
Table I. Demographic and clinicopathological characteristics of patients.

\begin{tabular}{lcccc}
\hline & $\begin{array}{c}\text { Patients with primary } \\
\text { bladder cancer (n=70) }\end{array}$ & $\begin{array}{c}\text { Patients with recurrent } \\
\text { bladder cancer (n=44) }\end{array}$ & $\begin{array}{c}\text { Healthy control } \\
\text { subjects (n=49) }\end{array}$ & $\begin{array}{c}\text { Patients with NMIBC without } \\
\text { current disease (n=61) }\end{array}$ \\
\hline $\begin{array}{l}\text { Age (median) } \\
\text { Men:women }\end{array}$ & $65(30-90)$ & $70(47-88)$ & $66(38-83)$ & $71(25-92)$ \\
Tumor stage & $49: 21$ & $35: 9$ & $42: 7$ & $41: 20$ \\
Carcinoma in situ & & & & - \\
Ta & 3 & 1 & - & - \\
T1 & 33 & 36 & - & - \\
T2-4 & 22 & 5 & - & - \\
Tumor grade & 15 & 3 & - & - \\
G1 & & & - & - \\
G2 & 19 & 31 & - & - \\
G3 & 25 & 7 & - & - \\
Average tumor size $(\mathrm{cm})$ & 26 & 6 & - & - \\
Average number of tumors & 3.6 & 1.5 & 3.4 & - \\
\hline
\end{tabular}

NMIBC: Non-muscle invasive bladder cancer.

(5). Accumulating reports have suggested that PLGF might be a useful prognostic marker of cancer progression. PLGF levels in plasma are upregulated and correlate with tumor stage, vascularity, recurrence, presence of metastases, and survival in various tumors (6-10). Meta-analysis indicated that elevated VEGF expression is associated with a poor prognosis in patients with bladder cancer (11).

Because PLGF modulates VEGF-A responses, we investigated their relationship, diagnostic accuracy and prognostic value in bladder cancer patients.

\section{Patients and Methods}

Patients. The study cohort included 240 individuals, of whom there were 50 healthy control subjects, 66 patients with a history of NMIBC without current disease and 124 consecutive patients with bladder cancer diagnosed from September 2011 to April 2013. In 8 patients, urothelial carcinoma was not histologically confirmed. After the exclusion of 8 more patients with a positive urine culture, there were 49 healthy control subjects, 61 patients with a history of NMIBC without current disease and 114 patients with bladder cancer. From 114 patients with bladder cancer, 70 patients had primary occurrence of bladder cancer and in 44 patients it was cancer recurrence, where the original histology was urothelial NMIBC. Demographic, clinical and pathological characteristics of the final cohort of 224 tested subjects are given in Table I.

Detailed inclusion and exclusion criteria were described in our previous study (12). Briefly, criteria for the inclusion of patients with tumor into the project were a suspicion of bladder tumor, during cystoscopy or during imaging examinations. Individuals in the group of healthy control subjects were without any evidence of malignant disease. Patients with a history of NMIBC without current disease had negative urinary cytology, taken 14 days prior to cystoscopy and negative cystoscopy on the day of their inclusion in the study cohort.
The follow-up began on the date of the transurethral resection of the bladder (TURB) and lasted until the time of death or until the last visit. All patients were examined at a 3-month interval by cystoscopy and urine cytology. Further controls were stratified according to the recurrence and progression risk pursuant to the EAU guidelines (13). The recurrence was defined as a new, non-muscleinvasive tumor occurring within the period longer than 3 months after the initial operation. Disease progression was defined as the occurrence of a muscle-invasive tumor (stage T2 or higher) or metastatic disease. The treatment consisted of repeated TURB with or without intravesical administration of bacillus Calmette-Guérin (BCG) therapy or intravesical chemotherapy with mitomycin $\mathrm{C}$ (MMC). Single immediate intravesical instillation of chemotherapy was not administered to any patient during the study period.

Sample and data collecting. After obtaining the local ethics committee approval, urine and plasma samples were collected prospectively from September 2011 to April 2013. Blood samples were collected after an overnight fast by puncture of the cubital vein into tubes with EDTA (ethylene diamine tetraacetic acid). Blood was centrifuged in a standard laboratory centrifuge for $10 \mathrm{~min}$ at $3000 \mathrm{rpm}$ (revolutions per minute). Plasma and urine samples were stored at $-80^{\circ} \mathrm{C}$ until analysis. Urine VEGF-A levels were measured during our previous project (12) while plasma VEGF-A, urine and plasma PLGF levels were examined later, on archived samples collected during the original project.

Biomarker analysis. Levels of the evaluated markers that included vascular endothelial growth factor-A (VEGF-A, eBioscience Inc., San Diego, USA) and placental growth factor (PLGF, RD Systems, Minneapolis, MN, USA) were analyzed. Due to an inevitable variability of the urine volume and different time for which urine was in contact with the bladder walls, the obtained urinary values of individual biomarkers were standardized to the value of urinary creatinine concentration (14).

Data analysis. Basic statistical data, i.e. mean, standard deviation, median, inter-quartile range, minimum and maximum were 
Table II. Mean and median values of PLGF and VEGF-A in urine and plasma tested by the ELISA method. Comparison of 70 patients with primary occurrence of tumor and 49 healthy control subjects, and of 44 patients with cancer recurrence and 61 patients with the history of NBIMC without recurrence.

\begin{tabular}{|c|c|c|c|c|c|}
\hline \multirow[t]{2}{*}{ Biomarker } & \multicolumn{2}{|c|}{ Primary carcinoma } & \multicolumn{2}{|c|}{ Healthy control subjects } & \multirow[t]{2}{*}{$p$-Value } \\
\hline & $\begin{array}{l}\text { mean } \pm \text { standard } \\
\text { deviation }\end{array}$ & $\begin{array}{l}\text { median } \\
(\min , \max )\end{array}$ & $\begin{array}{l}\text { mean } \pm \text { standard } \\
\text { deviation }\end{array}$ & $\begin{array}{l}\text { median } \\
(\min , \max )\end{array}$ & \\
\hline $\begin{array}{l}\text { Urinary PLGF }(\mathrm{pg} / \mathrm{ml}) \\
\text { Urinary PLGF }(\mathrm{pg} / \mathrm{ml}) /\end{array}$ & $43.3 \pm 80.0$ & $22.6(0.0,639.3)$ & $25.0 \pm 21.4$ & $17.5(0.0,118.7)$ & 0.087 \\
\hline Creatinine $(\mathrm{mmol} / \mathrm{l})$ & $4.0 \pm 8.0$ & $2.6(0.0,64.6)$ & $2.0 \pm 1.3$ & $1.9(0.0,6.3)$ & 0.003 \\
\hline Plasma PLGF (pg/ml) & $8.2 \pm 5.85$ & $9.0(0.0,34.6)$ & $5.7 \pm 4.0$ & $6.0(0.00,13.4)$ & 0.005 \\
\hline Urinary VEGF-A (pg/ml) & $718 \pm 588$ & $545(82,2200)$ & $405 \pm 376$ & $315(12,1817)$ & 0.001 \\
\hline Urinary VEGF-A (pg/ml)/ & & & & & \\
\hline Creatinine $(\mathrm{mmol} / \mathrm{l})$ & $76 \pm 98$ & $51(9,729)$ & $43 \pm 49$ & $23(3,251)$ & $<0.001$ \\
\hline Plasma VEGF-A (pg/ml) & $153 \pm 259$ & $88(31,2000)$ & $96 \pm 82$ & $65(31,443)$ & 0.106 , n.s. \\
\hline \multirow[t]{2}{*}{ Biomarker } & \multicolumn{2}{|c|}{ Recurrent carcinoma } & \multicolumn{2}{|c|}{$\begin{array}{l}\text { Patients with the history of } \\
\text { NMIBC without recurrence }\end{array}$} & $p$-Value \\
\hline & $\begin{array}{l}\text { mean } \pm \text { standard } \\
\text { deviation }\end{array}$ & $\begin{array}{c}\text { median } \\
(\min , \max )\end{array}$ & $\begin{array}{l}\text { mean } \pm \text { standard } \\
\text { deviation }\end{array}$ & $\begin{array}{c}\text { median } \\
(\min , \max )\end{array}$ & \\
\hline Urinary PLGF (pg/ml) & $19.4 \pm 15.0$ & $15.6(0.0,70.1)$ & $19.9 \pm 15.9$ & $17.7(0.0,65.9)$ & 0.961 , n.s. \\
\hline \multicolumn{6}{|l|}{ Urinary PLGF $(\mathrm{pg} / \mathrm{ml}) /$} \\
\hline Creatinine $(\mathrm{mmol} / \mathrm{l})$ & $1.8 \pm 1.1$ & $1.5(0.0,4.7)$ & $1.8 \pm 1.2$ & $1.9(0.00,5.1)$ & 0.611 , n.s. \\
\hline Plasma PLGF (pg/ml) & $10.2 \pm 5.4$ & $10.0(0.0,28.4)$ & $7.1 \pm 4.7$ & $6.8(0.0,23.8)$ & 0.001 \\
\hline Urinary VEGF-A (pg/ml) & $400 \pm 357$ & $342(42,2008)$ & $469 \pm 366$ & $333(38,1794)$ & 0.567 , n.s. \\
\hline \multicolumn{6}{|l|}{ Urinary VEGF-A $(\mathrm{pg} / \mathrm{ml}) /$} \\
\hline Creatinine $(\mathrm{mmol} / \mathrm{l})$ & $76 \pm 94$ & $50(9,729)$ & $39 \pm 25$ & $31(15,126)$ & $<0.001$ \\
\hline Plasma VEGF-A (pg/ml) & $191 \pm 217$ & $104(31,860)$ & $136 \pm 155$ & $93(31,934)$ & 0.297 , n.s. \\
\hline
\end{tabular}

PLGF: Placental growth factor; VEGF-A: vascular endothelial growth factor A; n.s.: not significant.

calculated for the obtained parameters in the whole set and in individual groups and subgroups. Spearman's rank correlation coefficient was used to determine the correlation between the studied parameters. Correlations between individual biomarkers and bladder cancer were determined by Wilcoxon test (Rank Sums). Non-parametric ROC (receiver operating characteristic) curves were created. Relative potential of the markers to identify bladder carcinoma was specified by the calculation of area under the ROC curve (AUC). Statistical significance was set at $p<0.05$ and all reported $\mathrm{p}$ values were 2 -sided.

For statistical analysis, the following baseline variables were considered for their prognostic value: stage (Ta, T1), grade (G1, G2, G3), multiplicity (multiple $\times$ solitary), presence of CIS, tumour size $(<3 \mathrm{~cm} \times>3 \mathrm{~cm}$ in diameter), administration of intravesical BCG, administration of intravesical chemotherapy. Recurrence-free status was analysed using the Kaplan-Meier method; the log-rank test was used to compare curves for two or more groups $(15,16)$. For all analyses $p<0.05$ was considered statistically significant. Patients' death of other causes, or their being lost to further examination, was censored at the date of the last follow-up. Cox's proportional hazards model was used for the multivariate analysis of prognostic parameters to estimate the relative risk and to select independent prognostic factors. The results were expressed as a hazard ratio (HR), which was derived from the estimated regression coefficients with their $95 \%$ confidence intervals (17). Statistical analysis was carried out using the SAS 9.4 software (SAS Institute Inc., Cary, NC, USA).

\section{Results}

Diagnostic accuracy of PLGF in primary bladder cancer. The level of PLGF in urine samples was significantly elevated in patients with primary bladder cancer compared to healthy individuals $(p=0.003)$. The differences in plasma levels of PLGF were also statistically significant $(p=0.005)$ (Table II). Urinary levels of PLGF correlated with the tumor stage $(p=0.026)$ and tumor size $(p=0.028)$. No correlation was found with the tumor grade or number of tumors. Plasma levels of PLGF did not correlate with any of these parameters. The correlation between plasma and urinary levels of PLGF was low (Spearman's rank correlation coefficient $0.199, p=0.098$ ). Urinary PLGF concentrations reached the sensitivity of $45.71 \%$ and specificity of $75.51 \%$ in primary bladder cancer detection; Area under the ROC curve (AUC) was 0.68 (Figure 1). Plasma PLGF concentrations provided the sensitivity of $51.42 \%$ and specificity of $75.51 \%$; AUC was 0.65 . 


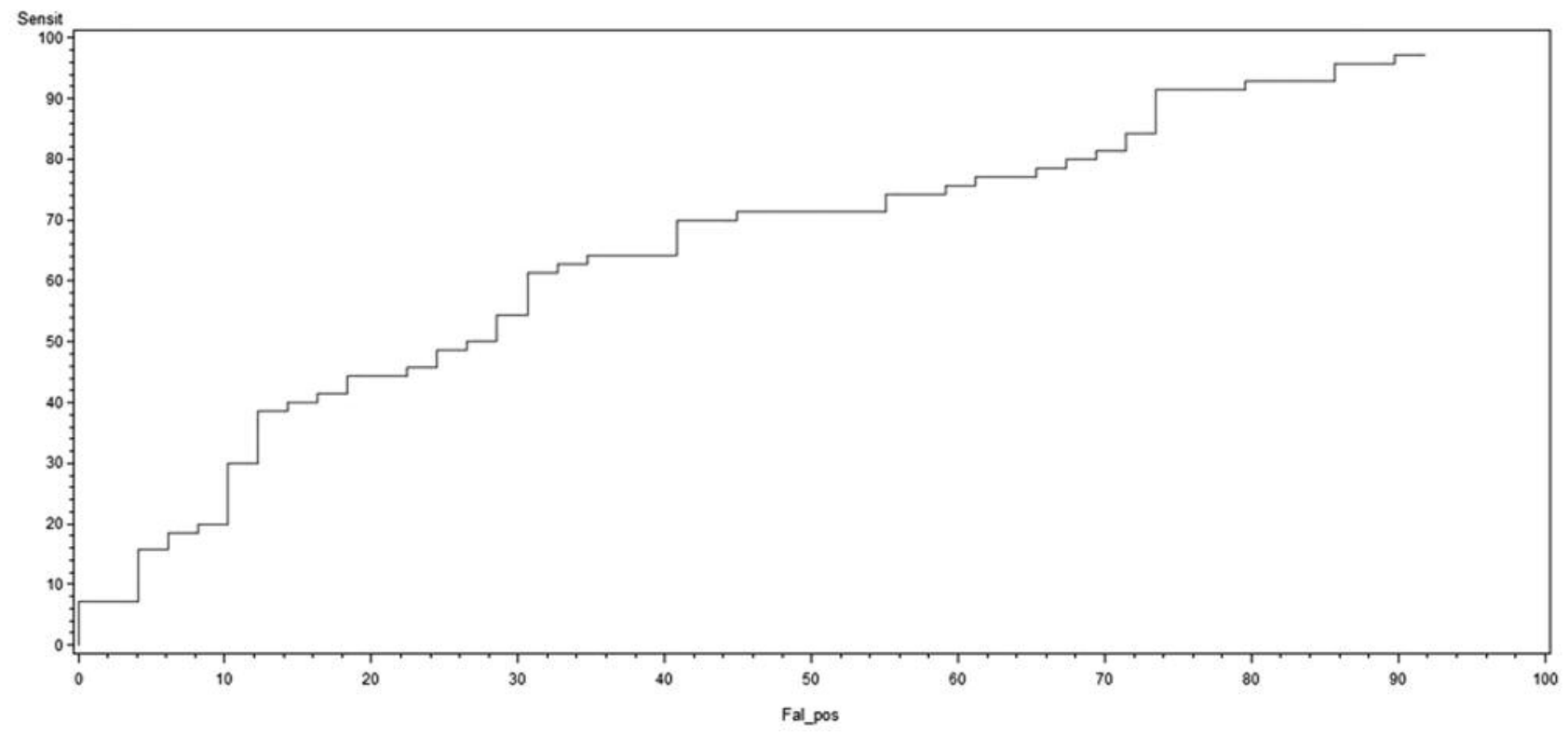

Figure 1. Urine PLGF level. Comparison of patients with primary occurrence of bladder carcinoma and healthy control subjects. AUC=0.68. PLGF: Placental growth factor; AUC: area under the curve; Sensit: sensitivity; Fal_pos: false positivity.

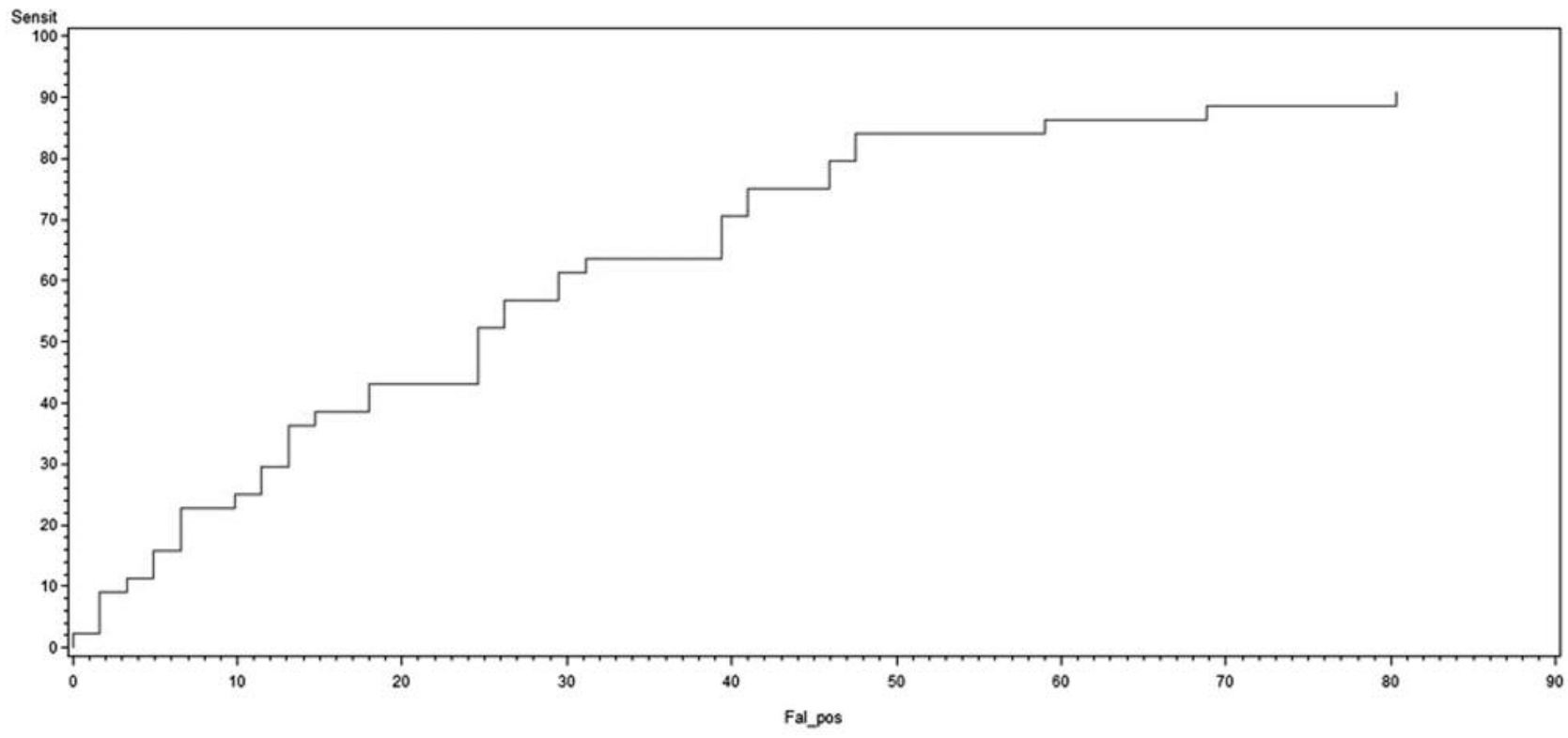

Figure 2. Plasma PLGF level: Comparison of patients with bladder cancer recurrence and patients with a history of NMIBC without current disease: $A U C=0.69$. PLGF: Placental growth factor; AUC: area under the curve; Sensit: sensitivity; Fal_pos: false positivity.

Diagnostic accuracy of PLGF in recurrent bladder cancer. Urinary levels of PLGF in patients with recurrent bladder cancer were not significantly different from the levels in patients without current disease $(p=0.61)$. On the other hand, plasma levels of PLGF were significantly elevated in case of tumor recurrence $(p=0.001)$ (Table II). Neither urinary nor plasma levels of PLGF correlated with tumor stage, grade, size or number of tumors. The correlation between urinary and plasma levels of PLGF was low (Spearman's rank correlation coefficient- $0.309, p=0.041$ ). 


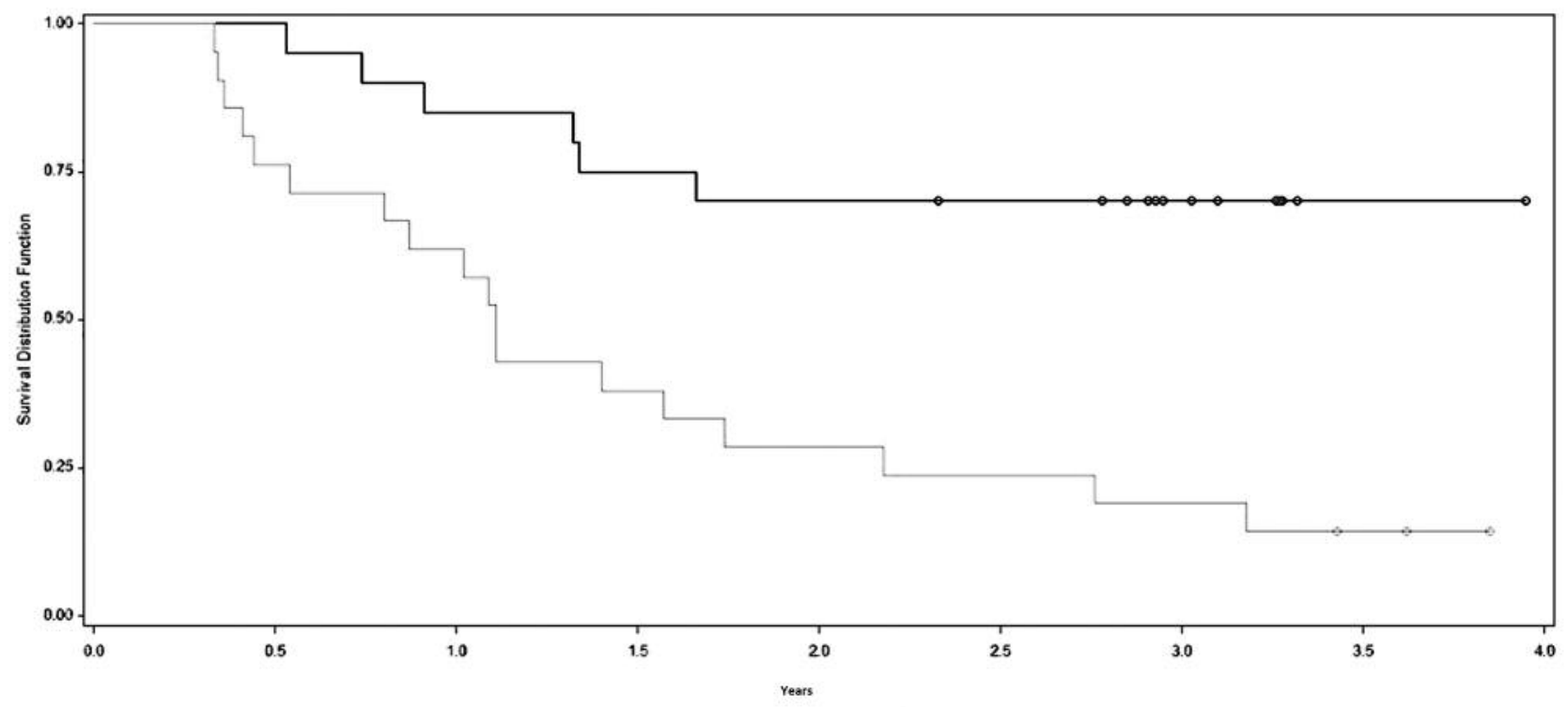

Figure 3. Kaplan-Meier curves of recurrence-free survival (log-rank test, $p<0.001)$. Blue line: patients with plasma PLGF <10.09 pg/ml (20 patients). Red line: patients with plasma PLGF $>10.09 \mathrm{pg} / \mathrm{ml}$ (21 patients). PLGF: Placental growth factor.

Plasma PLGF concentrations reached the sensitivity of $52.27 \%$ and specificity of $75.41 \%$ in recurrent bladder cancer detection; AUC was 0.69 (Figure 2).

Prognostic value of PLGF in primary NMIBC. From a total of 70 evaluated patients, 55 patients were diagnosed with NMIBC. Median of the follow-up was 3.2 years. Tumor recurrence was observed in 24 patients, tumor progression in 3 patients, 3 patients died due to progression of bladder cancer and 3 patients died from other causes. Due to a low number of events, analyses of progression free survival (PFS), overall (OS) and cancer-specific survival (CSS) are not presented. Patients with urinary level of PLGF higher than $82.33 \mathrm{pg} / \mathrm{ml}$ were at three times higher risk of tumor recurrence $(p=0.0237)$, HR 2.985 (95\% confidence interval $(C I)=1.105-8.061)$. In plasma levels of PLGF, no statistically significant cut-off value was found in relation to tumor recurrence.

Multivariate analysis: The following factors were identified in multivariate analysis using the proportional hazard model (Cox's regression): stage, grade, tumor multiplicity, tumor size, presence of carcinoma in situ (CIS), PLGF level in urine, PLGF level in plasma, VEGF-A level in urine, VEGF-A level in plasma, intravesical chemotherapy with mitomycin C (MMC) yes-no, intravesical BCG yes-no. The only variable that provided independent prognostic information in relation to the risk of tumor recurrence was the plasma level of PLGF and plasma level of VEGF-A (Table III).
Prognostic value of PLGF in recurrent NMIBC. From a total of 44 evaluated patients, 41 patients were diagnosed with NMIBC. Median of follow-up was 3.3 years. Tumour recurrence was observed in 22 patients, tumour progression in 3 patients, 3 patients died due to progression of bladder cancer and 5 patients died from other causes. Due to low number of events, analyses of PFS, OS and CSS have not been presented. Patients with urinary level of PLGF higher than $32.71 \mathrm{pg} / \mathrm{ml}$ were at 11.4 higher risk of tumour recurrence $(p<0.0001)$, HR $11.416(95 \% \mathrm{CI}=3.467-37.591)$. Elevated plasma levels of PLGF were also associated with the risk of tumour recurrence. Patients with the PLGF level in plasma higher than $10.09 \mathrm{pg} / \mathrm{ml}$ were at 5.1-fold higher risk of tumor recurrence $(p=0.0015)$, HR 5.115 (95\% CI=1.874-13.962) (Figure 3).

Multivariate analysis: The identified independent prognostic factors related to tumour recurrence were: plasma level of PLGF, urinary level of PLGF, tumor grade and administration of intravesical chemotherapy (Table III).

\section{Discussion}

We have evaluated diagnostic accuracy and prognostic performance of urinary and plasma level of PLGF in patients with primary and recurrent bladder cancer. We have measured levels of urinary and plasma VEGF-A in the same study population. While VEGF-A was already described as a component of variety of multi-marker diagnostic tests and its prognostic value in bladder cancer patients was reported, 
Table III. Multivariate Cox's proportional hazards model analysis - independent prognostic factors for the prediction of tumour recurrence in primary and recurrent $N M I B C$.

\begin{tabular}{lcrcr}
\hline Bladder cancer & Variable & HR & 95\%CI & $p$-Value \\
\hline Primary & Plasmac PLGF (cut-off $15.0 \mathrm{pg} / \mathrm{ml}$ ) & 4.120 & $1.302-13.037$ & 0.016 \\
Primary & Plasma VEGFA (cut-off $126.6 \mathrm{pg} / \mathrm{ml}$ ) & 3.149 & $1.326-7.479$ & 0.009 \\
Recurrent & Urinary PLGF (cut-off $-5.34 \mathrm{pg} / \mathrm{ml}$ ) & 11.192 & $3.238-38.683$ & $<0.001$ \\
Recurrent & Plasma PLGF (cut-off $14.2 \mathrm{pg} / \mathrm{ml}$ ) & 4.423 & $1.375-14.225$ & 0.013 \\
Recurrent & Tumor Grade & 3.354 & $1.678-6.701$ & $<0.001$ \\
Recurrent & Intravesical Chemotherapy (MMC) & 0.155 & $0.052-0.466$ & $<0.001$ \\
\hline
\end{tabular}

CI: Confidence interval; HR: hazard ratio; MMC: Mitomycin C; PLGF: placental growth factor; VEGF-A: vascular endothelial growth factor A.

Table IV. Comparison of tumor characteristics between the group of patients with primary bladder cancer $(n=70)$ and recurrent bladder cancer $(n=44)$.

\begin{tabular}{lccc}
\hline & Primary bladder cancer & Recurrent bladder cancer & Chi-square test \\
\hline Tumor stage $(\operatorname{Ta} \times \mathrm{T} 1 \times \mathrm{T} 2-4)$ & $33 \times 22 \times 15$ & $36 \times 5 \times 3$ & 0.001 \\
Tumor grade $(\mathrm{G} 1 \times \mathrm{G} 2 \times \mathrm{G} 3)$ & $19 \times 25 \times 26$ & $31 \times 7 \times 6$ & $<0.001$ \\
Number of tumors $($ mean) & 2.3 & 3.4 & 0.005 \\
Tumor size (diameter, cm) & 3.6 & 1.5 & $<0.001$ \\
Concomitant Cis & 3 & 1 & $\mathrm{NV}$ \\
\hline
\end{tabular}

NV: Chi-Square test is not valid; Cis: carcinoma in situ.

no study evaluating PLGF as a diagnostic or prognostic marker of bladder cancer has been published to date (18-21).

We found out comparable diagnostic accuracy of PLGF and VEGF-A except the detection of recurrent bladder cancer. In this clinical situation, PLGF concentration in plasma was more accurate. The prognostic performance was more pronounced in urinary and plasma levels of PLGF, compared to VEGF-A levels. In primary tumors, both urinary and plasma levels of PLGF were at the time of diagnosis significantly associated with the risk of recurrence. In VEGF-A, it was only urinary and not plasma levels. Independent prognostic information in multivariate analysis provided both plasma levels of PLGF and VEGF-A. In recurrent tumors, both urinary and plasma levels of PLGF were at the time of diagnosis significantly associated with the risk of further recurrence. In VEGF-A, it was only plasma levels. Plasma and urinary levels of PLGF provided independent prognostic information in multivariate analysis while neither plasma VEGF-A nor urinary VEGF-A had a statistically significant prognostic value with respect to recurrence-free survival.

In both evaluated markers, we found significantly elevated urinary levels in primary bladder carcinomas and insignificant differences in recurrent bladder carcinomas. A comparison of urinary PLGF levels between the group of primary and recurrent carcinomas suggested that the mean level was significantly higher in primary tumors. A similarly significant difference was observed in VEGF-A in favour of primary carcinomas. Differences may have been caused by differences in clinical characteristics of tumors - in the group of patients with primary tumors, there were significantly more tumors of a higher stage and more larger tumors (Table IV).

PLGF and VEGF-A can be considered as valid diagnostic tests for the detection of primary urinary bladder cancer. With respect to the AUC values, they are eligible as a part of a multi-marker test rather than a single-marker test. Neither of these markers is suitable as a urine test for the detection of small recurrent tumors. From the clinical point of view, plasma levels of PLGF in recurrent carcinomas can be considered as a valid diagnostic test with the value of AUC 0.69. Moreover, this factor can help identify patients at risk of future recurrence.

Results of published studies imply that the elevated PLGF and VEGF-A expression is associated with the risk of tumor progression, metastases development and shorter survival of patients in a number of solid tumors like larynx carcinoma, esophageal carcinoma, small-cell lung carcinoma, hepatocellular carcinoma, malignant pleural mesothelioma and neuroendocrine tumors (22-29). In 
patients with urinary bladder carcinoma, PLGF has not been tested as a prognostic marker to date. In our study cohort, most of the patients were diagnosed with NMIBC, so we observed only minimal progression and tumorassociated deaths during the follow-up. Meaningful analyses of PFS and CSS were not possible. The primary objective of our study was to determine whether the evaluated markers could be useful in determining the diagnosis of primary and recurrent bladder cancer. Therefore, we did not investigate the extent of expression of PLGF and VEGF-A in tumor tissue and we focused on examining plasma and urinary levels of PLGF and VEGFA. Requirements of an ideal diagnostic marker include the ease of examination. Therefore, marker levels were investigated using the ELISA method. We also tried to determine whether, using a simple diagnostic test, we could also get prognostic information regarding the risk of recurrence in a subset of patients with NMIBC. Placental PLGF and VEGF-A as regulators of angiogenesis are essential for tumor growth and development of distant metastases, so it would be beneficial to further examine their prognostic value in another set of patients, e.g. in patients with $\mathrm{T} 1$ carcinoma or MIBC, and determine the relationship to the risk of progression, survival and type of treatment chosen.

According to our information, this is the first study that assesses the diagnostic accuracy and prognostic significance of urinary and serum levels of PLGF in patients with bladder carcinoma. Benefits of our study lie in its design, where there are compared primary bladder tumors with healthy control individuals and recurrences, compared to patients followed-up due to NMIBC. This allowed us to find a suitable marker for a particular clinical situation. A limit of our study was the small number of patients in individual groups and the short follow-up.

\section{Conclusion}

Urinary levels of PGF and VEGF-A are useful diagnostic tests for the detection of primary bladder carcinomas. Plasma levels of PLGF can be used as a diagnostic and prognostic marker in recurrent bladder cancer.

\section{Conflicts of Interest}

None.

\section{Acknowledgements}

The study was supported by research projects BBMRI_CZ LM2015089 and EF16 013/0001674 (European Regional Development Fund) and by project RVO-VFN 64165.

The Authors would like to express their gratitude to laboratory workers and nurses for their technical support and cooperation.

\section{References}

1 Sylvester RJ, van der Meijden APM, Oosterlinck W, Witjes JA, Bouffioux C, Denis L, Newling DW and Kurth K: Predicting recurrence and progression in individual patients with stage TaT1 bladder cancer using EORTC risk tables: a combined analysis of 2596 patients from seven EORTC trials. Eur Urol 49(3): 466-477, 2006.

2 Soukup V, Babjuk M, Bellmunt J, Dalbagni G, Giannarini G, Hakenberg OW, Herr H, Lechevallier E and Ribal MJ: Followup after surgical treatment of bladder cancer: a critical analysis of the literature. Eur Urol 62(2): 290-302, 2012.

3 Fahmy NM, Mahmud S and Aprikian AG: Delay in the surgical treatment of bladder cancer and survival: systematic review of the literature. Eur Urol 50(6): 1176-1182, 2006.

4 Carmeliet P: Angiogenesis in life, disease and medicine. Nature 438: 932-936, 2005.

5 Maae E, Olsen DA, Steffensen KD, Jakobsen EH, Brandslund I, Sørensen FB and Jakobsen A: Prognostic impact of placenta growth factor and vascular endothelial growth factor $\mathrm{A}$ in patients with breast cancer. Breast Cancer Res Treat 133(1): 257$265,2012$.

6 Matsumoto K, Suzuki K, Koike H, Hasumi M, Matsui H, Okugi $\mathrm{H}$, Shibata Y, Ito K and Yamanaka H: Placental growth factor gene expression in human prostate cancer and benign prostate hyperplasia. Anticancer Res 23(5A): 3767-3773, 2003.

7 Wei SC, Liang JT, Tsao PN, Hsieh FJ, Yu SC and Wong JM: Preoperative serum placenta growth factor level is a prognostic biomarker in colorectal cancer. Dis Colon Rectum 52(9): 16301636, 2009.

8 Ho MC, Chen CN, Lee H, Hsieh FJ, Shun CT, Chang CL, Lai YT and Lee PH: Placenta growth factor not vascular endothelial growth factor A or $\mathrm{C}$ can predict the early recurrence after radical resection of hepatocellular carcinoma. Cancer Lett 250(2): 237-249, 2007.

9 Escudero-Esparza A, Martin TA, Davies ML and Jiang WG: PGF isoforms, PLGF-1 and PGF-2, in colorectal cancer and the prognostic significance. Cancer Genomics Proteomics 6(4): 239246, 2009.

10 Nagaoka S, Yoshida T, Akiyoshi J, Akiba J, Hisamoto T, Yoshida Y, Abe M, Koga H, Toirimura T, Ueno T and Sata M: The ratio of serum placenta growth factor to soluble vascular endothelial growth factor receptor-1 predicts the prognosis of hepatocellular carcinoma. Oncol Rep 23(6): 1647-1654, 2010.

11 Huang YJ, Qi WX, He AN, Sun YJ, Shen Z and Yao Y: Prognostic value of tissue vascular endothelial growth factor expression in bladder cancer: a meta-analysis. Asian Pac J Cancer Prev 14(2): 645-649, 2013.

12 Soukup V, Kalousová M, Capoun O, Sobotka R, Breyl Z, Pešl M, Zima T and Hanuš T: Panel of Urinary Diagnostic Markers for Non-Invasive Detection of Primary and Recurrent Urothelial Urinary Bladder Carcinoma. Urol Int 95(1): 56-64, 2015.

13 Babjuk M, Böhle A, Burger M, Capoun O, Cohen D, Compérat EM, Hernández V, Kaasinen E, Palou J, Rouprêt M, van Rhijn BW, Shariat SF, Soukup V, Sylvester RJ and Zigeuner R: EAU Guidelines on Non-Muscle-invasive Urothelial Carcinoma of the Bladder: Update 2016. Eur Urol 71(3): 447-461, 2017.

14 Xylinas E, Kluth LA, Rieken M, Karakiewicz PI, Lotan Y and Shariat SF: Urine markers for detection and surveillance of bladder cancer. Urol Oncol 32(3): 222-229, 2014. 
15 Kaplan E and Meier P: Nonparametric estimation from incomplete observation. J Am Stat Assoc 53: 457-481, 1958.

16 Mantel N: Evaluation of survival data and two new rank order statistics arising in its consideration. Cancer Chemother Rep 50(3): 163-170, 1966.

17 Cox DR: Regression models and life-tables. J R Stat Soc 34: 187-220, 1972.

18 De Paoli M, Perco P, Mühlberger I, Lukas A, Pandha H, Morgan R, Feng GJ and Marquette C: Disease map-based biomarker selection and pre-validation for bladder cancer diagnostic. Biomarkers 20(5): 328-337, 2015.

19 Wieczorek E, Jablonowski Z, Tomasik B, Konecki T, Jablonska E, Gromadzinska J, Fendler W, Sosnowski M, Wasowicz W and Reszka E: MMP, VEGF and TIMP as prognostic factors in recurring bladder cancer. Clin Biochem 48(18): 1235-1240, 2015.

20 Chen LM, Chang M, Dai Y, Chai KX, Dyrskjøt L, SanchezCarbayo M, Szarvas T, Zwarthoff EC, Lokeshwar V, Jeronimo C, Parker AS, Ross S, Borre M, Orntoft TF, Jaeger T, Beukers W, Lopez LE, Henrique R, Young PR, Urquidi V, Goodison S and Rosser CJ: External validation of a multiplex urinary protein panel for the detection of bladder cancer in a multicenter cohort. Cancer Epidemiol Biomarkers Prev 23(9): 1804-1812, 2014.

21 Rosser CJ, Chang M, Dai Y, Ross S, Mengual L, Alcaraz A and Goodison S: Urinary protein biomarker panel for the detection of recurrent bladder cancer. Cancer Epidemiol Biomarkers Prev 23(7): 1340-1345, 2014.

22 Chen Y, Jiang T, Mao A and Xu J: Esophageal cancer stem cells express PLGF to increase cancer invasion through MMP9 activation. Tumour Biol 35(12): 12749-12755, 2014

23 Zhou X and Qi Y: PLGF inhibition impairs metastasis of larynx carcinoma through MMP3 downregulation. Tumour Biol 35(9): 9381-9386, 2014
24 Cheng SJ, Cheng SL, Lee JJ, Chen HM, Chang HH, Kok SH, Chiang ML and Kuo MY: Increased placenta growth factor mRNA level is significantly associated with progression, recurrence and poor prognosis of oral squamous cell carcinoma. J Formos Med Assoc 112(5): 253-258, 2013.

25 Hilfenhaus G, Göhrig A, Pape UF, Neumann T, Jann H, Zdunek D, Hess G, Stassen JM, Wiedenmann B, Detjen K, Pavel M and Fischer C: Placental growth factor supports neuroendocrine tumor growth and predicts disease prognosis in patients. Endocr Relat Cancer 20(3): 305-319, 2013.

26 Li B, Wang C, Zhang Y, Zhao XY, Huang B, Wu PF, Li Q, Li H, Liu YS, Cao LY, Dai WM, Fang WG, Shang DS, Cao L, Zhao WD and Chen YH: Elevated PLGF contributes to smallcell lung cancer brain metastasis. Oncogene 32(24): 2952-2962, 2013.

$27 \mathrm{Xu}$ HX, Zhu XD, Zhuang PY, Zhang JB, Zhang W, Kong LQ, Wang WQ, Liang Y, Wu WZ, Wang L, Fan J, Tang ZY and Sun HC: Expression and prognostic significance of placental growth factor in hepatocellular carcinoma and peritumoral liver tissue. Int J Cancer 128(7): 1559-1569, 2011.

28 Pompeo E, Albonici L, Doldo E, Orlandi A, Manzari V, Modesti A and Mineo TC: Placenta growth factor expression has prognostic value in malignant pleural mesothelioma. Ann Thorac Surg 88(2): 426-431, 2009.

29 Chen CN, Hsieh FJ, Cheng YM, Cheng WF, Su YN, Chang KJ and Lee PH: The significance of placenta growth factor in angiogenesis and clinical outcome of human gastric cancer. Cancer Lett 213(1): 73-82, 2004.

Received October 28, 2017

Revised November 8, 2017

Accepted November 9, 2017 